\title{
Automatic Phase-Shift Method for Islanding Detection of Grid-Connected Photovoltaic Inverters
}

\author{
Guo-Kiang Hung, Chih-Chang Chang, and Chern-Lin Chen, Senior Member, IEEE
}

\begin{abstract}
The traditional frequency-shift methods for islanding detection of grid-connected PV inverters-the active frequency drift method and the slip-mode frequency-shift method-become ineffective under certain paralleled RLC loads. The automatic phase-shift method is proposed in this paper to alleviate this problem. The method is based on the phase shift of the sinusoidal inverter output current. When the utility malfunctions, the phase-shift algorithm keeps the frequency of the inverter terminal voltage deviating until the protection circuit is triggered. Simulation and experiments are performed for verification.
\end{abstract}

Index Terms-Automatic phase shift, grid-connected photovoltaic inverters, inverters, islanding detection.

\section{INTRODUCTION}

I SLANDING phenomenon of grid-connected photovoltaic (PV) inverters refers to their independent operation when the utility is disconnected. The local section energized by self-activated PV inverters becomes an "island" isolated from the remaining power system. Concern about such phenomenon is raised because it causes danger to uninformed maintenance personnel. Therefore, it is desirable to incorporate detection functions into PV inverters for protection. Islanding detection methods, which have been proposed, are generally classified into passive and active techniques. An inverter equipped with an overvoltage relay (OVR), an undervoltage relay (UVR), an overfrequency relay (OFR), and an underfrequency relay (UFR) [1] has the basic islanding detection capability. Once the voltage level or frequency at the terminal exceeds the preset normal range, the situation is regarded as utility malfunction. The inverter is forced to be shut down to prevent lasting islanding operation. However, such relays fail under source-load balanced conditions because the terminal voltage does not change in magnitude or in frequency without the utility. Other methods should be applied to enhance the detection ability. One of them is the voltage harmonics monitoring method. The method is mainly based on the nonlinear characteristics of power transformers in the distribution systems. Without the strong utility voltage source, the current injected from PV inverters into power transformers would cause large voltage harmonics. Continuous monitoring terminal voltages can effectively detect islanding operation when the harmonics level

Manuscript received July 26, 2001; revised February 27, 2002. This work was supported in part by the Industrial Development Bureau, Ministry of Economic Affairs, R.O.C., and Motech Industries Incorporated, Taipei, Taiwan, R.O.C.

G.-K. Hung and C.-L. Chen are with the Department of Electrical Engineering, National Taiwan University, Taipei, Taiwan, R.O.C. (e-mail: clchen@cc.ee.ntu.edu.tw).

C.-C. Chang is with the AmbitMicrosystems Co., Hsinchu, Taiwan, R.O.C.

Digital Object Identifier 10.1109/TEC.2002.808412 increases. Even though the test results from Rokko island, Japan [2]-[8] revealed that this is a rather effective detection method, a study [9] has shown that it is hard to select the trip threshold. Another method called phase jump detection method [4] monitors terminal voltages in a different way. PV inverters usually output currents in phase with the utility voltage for unity power factor. When the utility is disconnected, the phase angle between the output current and the terminal voltage of an inverter is determined by the load. An instant phase change of the voltage may occur and triggers protection circuits.

The detection methods mentioned before all depend on some kind of monitoring of inverter terminal voltages. They are classified as passive techniques. Their ability of islanding detection is not guaranteed for all load conditions, especially for source-load balanced conditions. As a result, active techniques are invented for enhancement. One simple active technique is to change output power of PV inverters periodically. This is effective to break source-load balanced conditions. However, the method is impractical because timing synchronization must be made among all of the inverters in a power system or it would not work due to the averaging effect [9], [10].

To avoid the problem, two frequency-shift methods are getting more attention recently. Both are based on the frequency shift of inverter output current without synchronization needed for islanding detection. One of them is the active frequency drift method (AFD) [9], [11]-[13]. When the utility is disconnected, phase difference between the terminal voltage and the output current of a PV inverter depends on the load. It is detected by the internal phase-locked-loop (PLL) circuitry. To eliminate the phase difference, the frequency of the inverter output current is forced to drift up or down. The intension is to make the frequency of the terminal voltage deviate from its nominal value until OFR or UFR is triggered. The other method is the slip-mode frequency-shift method (SMS) [9], [11]. It is similar to AFD except that the starting angle of the inverter output current also varies with frequency at each zero crossing of the terminal voltage. Nevertheless, it has been demonstrated that "nondetection zones" still exist [9], [14]. That is, the previously mentioned two methods become ineffective under certain load conditions, especially with paralleled RLC resonant loads.

In this paper, the nondetection possibilities of AFD and SMS are discussed first. Then, the automatic phase-shift method (APS) will be introduced to enhance the ability of islanding detection. A paralleled RLC circuit is used as a simplified ac load model [12]. Through the following analysis and simulation, it is presented that APS alleviates the nondetection problems of AFD and SMS. Finally, experimental results are provided for verification. 


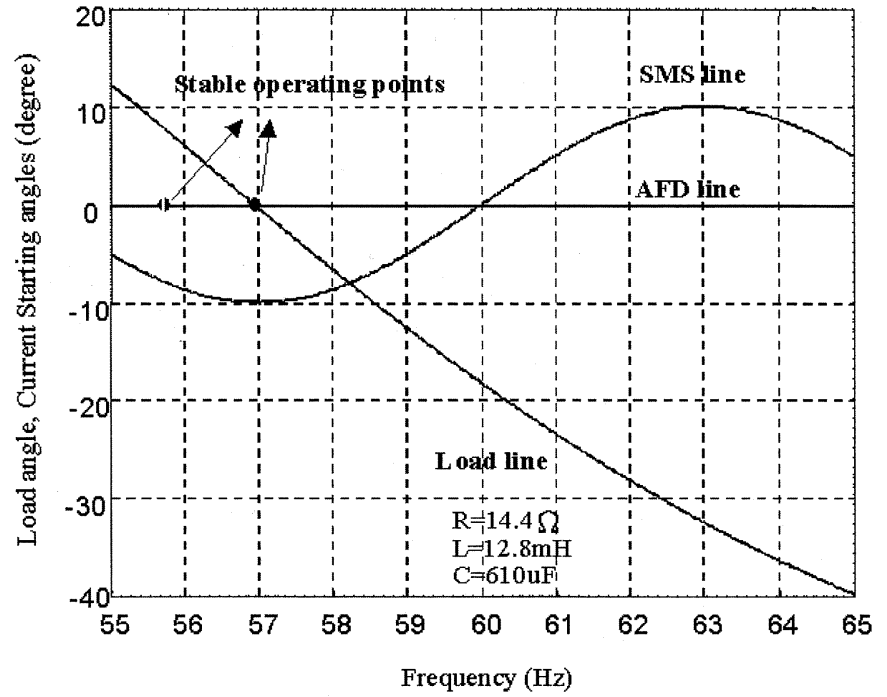

Fig. 1. Stable operating points with AFD and SMS.

\section{INHERENT ISLANDING NONDETECTION OF AFD AND SMS}

PV inverters are usually designed to output current in phase with the utility voltage to achieve unity-power-factor operation. For a digitally controlled inverter, zero crossings of the sinusoidal voltage waveform at the terminal are detected to synchronize the output current. The following analysis is based on digitally controlled PV inverters.

When the utility is disconnected from a PV inverter, the phase difference between its terminal voltage and output current is determined by the load. For example, the phase angle $\varphi$ of the voltage relative to the current of a paralleled RLC load depends on the operating frequency $f$

$$
\varphi=-\tan ^{-1}\left(R\left(2 \pi f C-\frac{1}{2 \pi f L}\right)\right) .
$$

If $\varphi$ is negative at line frequency, a phase lag of the terminal voltage is detected without the utility. For AFD, the terminal voltage is now regarded of low frequency. The frequency of the inverter output current is forced to drift down to see if the frequency of the terminal voltage slows down accordingly. The action continues until UFR is triggered. Unfortunately, as the frequency of the current drifts down, $\varphi$ becomes less and less negative. It is possible that under certain loads, a steady-state frequency would be reached with $\varphi=0$ before UFR is triggered.

On the other hand, there is a similar problem for SMS. Although the starting angle of the inverter output current is also changed with its frequency at each zero-crossing of the terminal voltage, a stable operating point still exists if the changing rate of $\varphi$ exceeds that of the starting angle with the algorithm [9]. Fig. 1 gives a better illustration. The $X$-axis is the frequency of the inverter output current. The $Y$-axis is $\varphi$, but also represents the starting angles of the inverter current with AFD and SMS. For AFD, the stable operating point lies at the intersection of the load line and the $X$-axis, where there is no phase difference between voltage and current. For SMS, assume that the starting angle of the inverter output current during the $k$ th voltage cycle

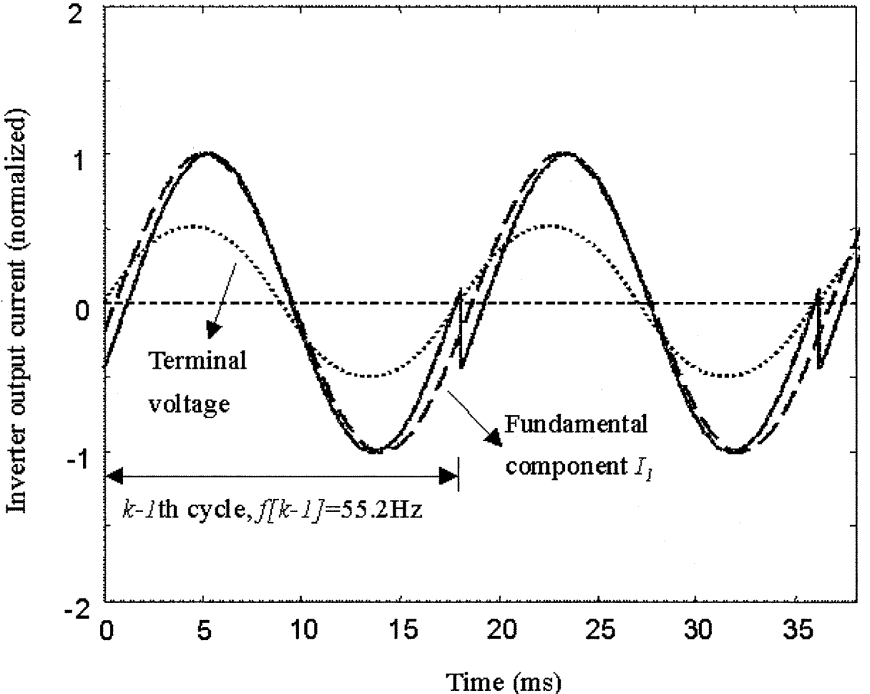

Fig. 2. Inverter output current waveform with modified SMS.

(the voltage cycle is defined as the time interval between sequential zero-crossings) is governed by

$$
\theta[k]=10^{\circ} \cdot \sin \left(\frac{\pi}{2} \cdot \frac{f[k-1]-60 \mathrm{~Hz}}{3 \mathrm{~Hz}}\right)
$$

where $f[k-1]$ is the measured frequency of the previous voltage cycle [11]. $\theta$ has the maximum value when the frequency deviation reaches $3 \mathrm{~Hz}$. If the absolute value of the slope of the load line is greater than that of the SMS line, there is a stable operating point, where $\varphi$ and $\theta$ sum to be zero. If the frequency is not low enough to trigger UFR, the method fails.

\section{Failure Mechanism of Phase- Shift Technique}

It has been shown that the main cause of the nondetection problem of AFD and SMS comes from that the load angle is frequency dependent. As a result, modifications should be made to SMS to avoid the situation. That is, only the starting angle of the inverter current is changed for islanding detection while the frequency remains constant. The phase-shift technique is adopted rather than the frequency-shift one. The method used here is named as the modified SMS. For example, if the $k$ th starting angle of the inverter current is a linear function of the voltage frequency

$$
\theta_{M-S M S}[k]=\frac{1}{\alpha} \cdot\left(\frac{f[k-1]-60 \mathrm{~Hz}}{60 \mathrm{~Hz}}\right) \cdot 360^{\circ}
$$

then for a lagging load at line frequency, the terminal voltage lags the inverter current and $f[k-1]<60 \mathrm{~Hz}$. The voltage cycle is supposed to last longer each time $\theta_{M-S M S}[k]$ gets more negative because the phase difference is fixed by the load. The positive-feedback algorithm should keep the frequency of the terminal voltage lower and lower cycle by cycle.

Unfortunately, this is not the case. A stable operating point would still be reached. Although the inverter output current does not change its frequency, the starting angle is reset at each zero-crossing of the terminal voltage. The fundamental frequency of the inverter current is subject to the voltage period. The phase angle of this fundamental component at each zero-crossing is also slightly moved. Refer to Fig. 2, for example, if $f[k-1]=55.2 \mathrm{~Hz}$ with $\alpha=1.2$ is substituted into 


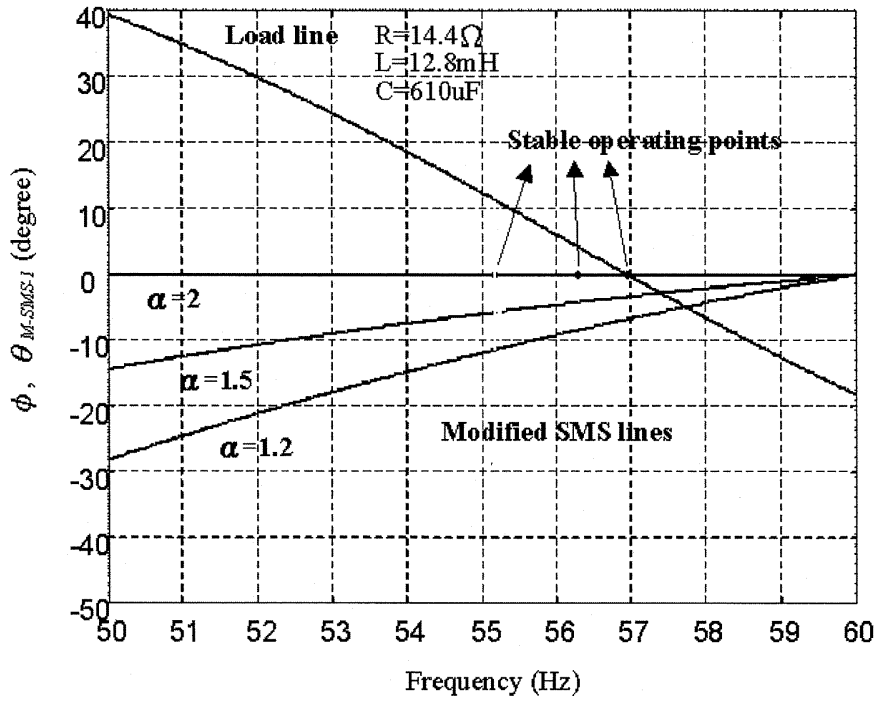

Fig. 3. Stable operating points with modified SMS.

(3), then $\theta_{M-S M S}[k]=24^{\circ}$ and the inverter current during the $k$ th voltage cycle can be written as

$$
I[k]=\left.\sin \left(2 \pi \cdot 60 \cdot t-24^{\circ}\right)\right|_{t=0} ^{t=(1 / 55.2) \mathrm{Hz}}
$$

assuming that $f[k]$ is also $55.2 \mathrm{~Hz}$. The frequency of its fundamental component $I_{1}[k]$ will also be $55.2 \mathrm{~Hz}$, no longer $60 \mathrm{~Hz}$

$$
I_{1}[k]=\sin \left(2 \pi \cdot 55.2 \cdot t-11.4^{\circ}\right) .
$$

The phase angle $\theta_{M-S M S-1}[k]$ of $I_{1}[k-1]$ is changed to be $11.4^{\circ}$. This phenomenon results in nondetection as applying SMS.

In Fig. 3, the modified SMS lines represent the phase-frequency relationship of the fundamental component of the inverter output current. The stable operating points are predicted at which $\theta_{M-S M S-1}[k]$ and $\varphi$ sum zero.

\section{Automatic Phase-Shift Method}

To solve this problem, the automatic phase shift method (APS) is proposed. The flow diagram of the algorithm is shown in Fig. 4. At the $k$ th zero-crossing of the terminal voltage, frequency of the previous voltage cycle is first measured. The starting angle $\theta_{A P S}[k]$ of the inverter output current is changed according to $f[k-1]$, but the frequency remains at nominal line frequency

$$
\theta_{A P S}[k]=\frac{1}{\alpha} \cdot\left(\frac{f[k-1]-60 \mathrm{~Hz}}{60 \mathrm{~Hz}}\right) \cdot 360^{\circ}+\theta_{\circ}[k] .
$$

Once the steady-state frequency of the terminal voltage reaches before UFR or OFR is triggered, the additional phase shift $\theta_{0}$ is also changed as

$$
\theta_{o}[k]=\theta_{o}[k-1]+\Delta \theta \times \operatorname{sgn}\left(\Delta f_{s} s\right)
$$

where

$$
\begin{array}{ll}
\Delta \theta & \text { constant; } \\
\Delta f_{s s} & \text { change of steady-state frequency; } \\
\theta_{o}[k] & 0 ; \\
\forall k & \leq 0 ; \\
\operatorname{sgn}\left(\Delta f_{s s}\right) & \begin{cases}1, & \Delta f_{s s}>0 \\
0, & \Delta f_{s s}=0 \\
-1, & \Delta f_{s s}<0\end{cases}
\end{array}
$$

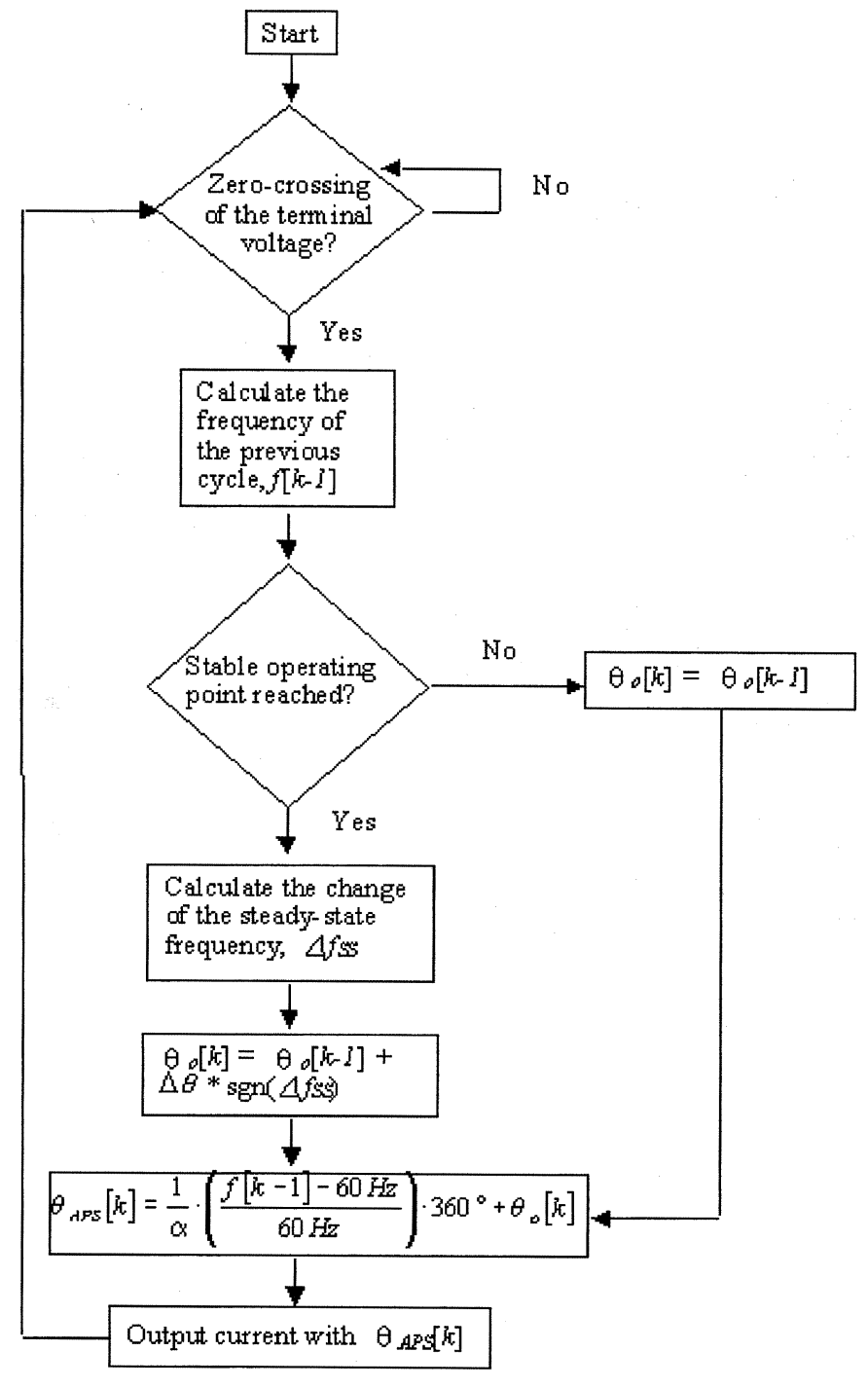

Fig. 4. Flow diagram of APS.

If the steady-state frequency varies from 60 to $59 \mathrm{~Hz}$, an additional phase angle $\Delta \theta$ will be subtracted from $\theta_{o}$ to break the stable operating point. Another steady-state frequency may be reached again, but for a lagging load at line frequency, $\theta_{o}$ gets larger and larger in magnitude. $\theta_{A P S}$ becomes more and more negative and so does the phase angle $\theta_{A P S-1}$ of the fundamental current component. If $\Delta \theta$ is taken as $3.6^{\circ}$ for example, referring to Fig. 5, the step changes of $\theta_{o}$ keep the steady-state frequency deviating. The algorithm guarantees that UFR or OFR will be triggered eventually. As to the normal line frequency drifting, for a deviation of $0.5 \mathrm{~Hz}, \theta_{A P S}$ is $4.1^{\circ}$ with $\alpha=2$.

On the other hand, if there is more than one inverter operating in parallel, all equipped with APS but with different values of $\alpha$ and $\Delta \theta$, the method also works. The values of $\alpha$ and $\Delta \theta$ relate to the starting angles of the sinusoidal inverter output current and its fundamental component. The fundamental frequency of inverter current is not affected, but is subjected to the terminal voltage, which has been proven in the previous section. Thus, the fundamental components of all inverter output currents will be of the same frequency but with different phase angles. It is known that the sum of sinusoids of the same frequency but 


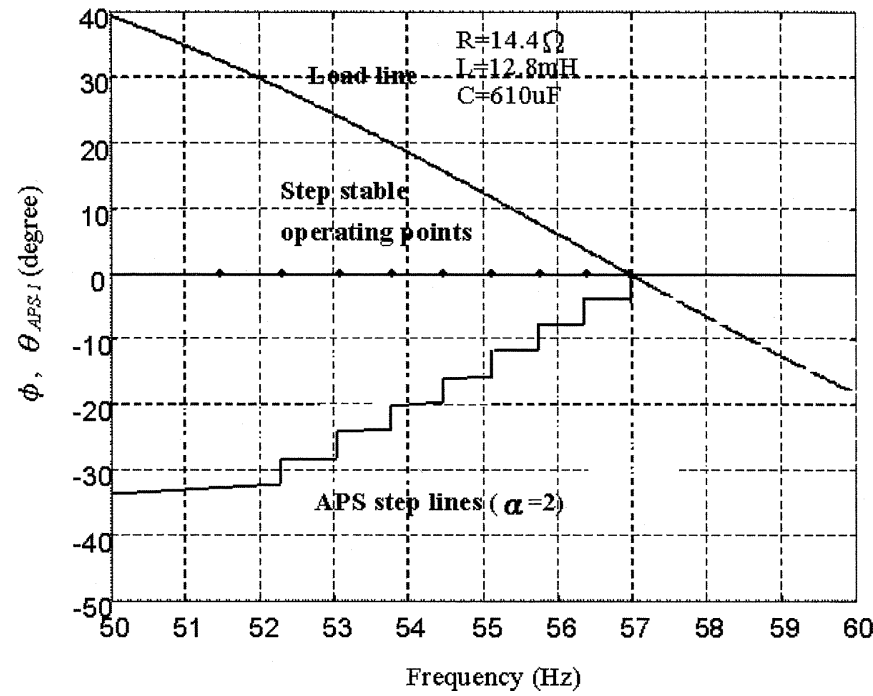

Fig. 5. Steady-state frequency jump with APS.

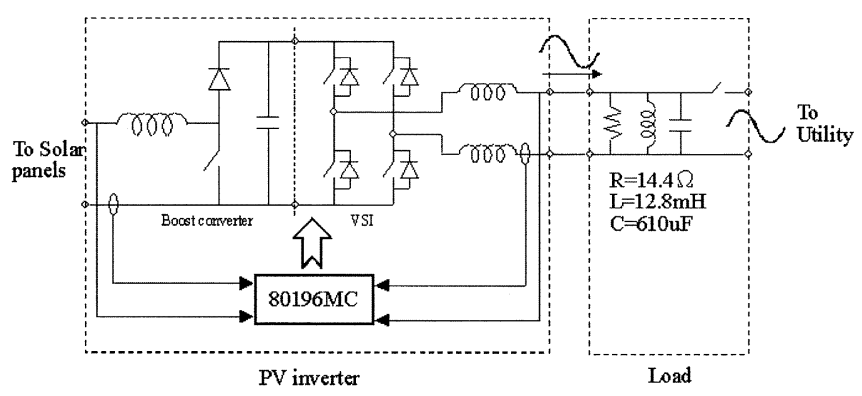

Fig. 6. Experimental circuit diagram.

with different angles is also a sinusoid, where the frequency remains unchanged with an effective phase angle as the result. As a result, the fundamental load current, which is the sum of fundamental components of all inverter currents, has the effective phase angle and the same frequency with the terminal voltage. The positive feedback of APS also keeps this effective phase angle deviating.

Although the effectiveness of APS is based on the initial phase difference between the inverter output current and the terminal voltage when the utility is disconnected, it still works for purely resistive loads or paralleled RLC loads with resonant frequency equal to line frequency. It is due to that in actual systems, that there are always noise perturbations or frequency detection errors [9]. Alternatively, the inverter output current waveform can be distorted for detection of such kinds of loads [12].

\section{EXPERIMENTAL RESULTS}

A 1-kW PV inverter is constructed for experiments. The circuit diagram is shown in Fig. 6. The power stage consists of a boost converter, followed by a voltage-source inverter (VSI). An Intel $80196 \mathrm{MC}$ microprocessor is used as the main controller. The boost converter provides a stable dc voltage source from an unregulated output voltage of solar panels. The VSI acts as a sinusoidal current source. The maximum power point tracking

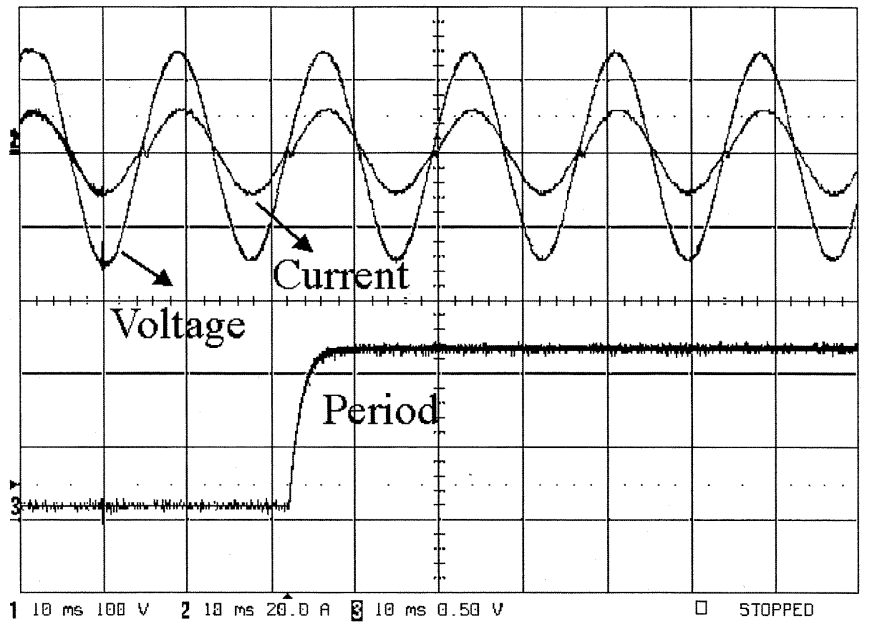

Fig. 7. Experimental result with modified SMS. (CH1: terminal voltage, 100 V/div; $\mathrm{CH} 2$ : inverter output current, $20 \mathrm{~A} / \mathrm{div}$; $\mathrm{CH} 3$ : period of terminal voltage, $0.3 \mathrm{~ms} / \mathrm{div}, 0 \mathrm{~V}$ represents $1 / 60 \mathrm{~Hz}$; TIME: $10 \mathrm{~ms} / \mathrm{div}$ ).

(MPPT) program of the controller determines the output current amplitude, while the zero-crossings of the terminal voltage are detected to synchronize the current with the utility voltage. The $\mathrm{PV}$ inverter is loaded by a paralleled RLC circuit with the same values used in the simulations. The load is designed to have a resonant frequency of $57 \mathrm{~Hz}$. Before the utility is disconnected, the inverter is made to output current of approximately $8 \mathrm{~A}$ (115 $\mathrm{VAC} / 14.4 \Omega$ ). This is to maintain the terminal voltage not to trigger UVR or OVR without the utility.

The modified SMS with $\alpha=2$ and $\theta_{\circ}[k]=0$ is applied first. It can be found from Fig. 7 that a steady-state frequency reaches approximately $57 \mathrm{~Hz}$, which corresponds to the simulation result in Fig. 3. The period of the terminal voltage is calculated by the microprocessor and is output via a digital-to-analog converter (DAC) to show the frequency variation.

APS with $\alpha=2$ is also programmed for experiment. Due to the restricted resolution of the microprocessor used, a stable operating point is defined as that the period variation of the terminal voltage remains within $0.2 \mathrm{~ms}$ for ten cycles. Besides, $\theta_{o}$ is set to be changed for eight times at most. The result is shown in Fig. 8. It can be observed that the steady-state frequency varies step by step and finally reaches approximately $51.5 \mathrm{~Hz}$, closed to the prediction value in Fig. 5 .

\section{CONCLUSION}

Frequency-shift methods were considered the most effective techniques for islanding detection of grid-connected PV inverters. However, they bear nondetection possibilities for paralleled RLC loads. The main cause of the islanding nondetection of AFD and SMS is first analyzed in this paper. It is found that because the phase angle of a paralleled RLC load depends on the operating frequency, the two frequency-shift algorithms have possibilities of making stable operation of PV inverters. The automatic phase-shift method (APS) is proposed to alleviate this problem. With APS, only the starting angle of the inverter output current is changed according to the frequency of the inverter terminal voltage. An additional phase shift is introduced each time the frequency of the terminal voltage stabilizes. The algorithm guarantees that the frequency 


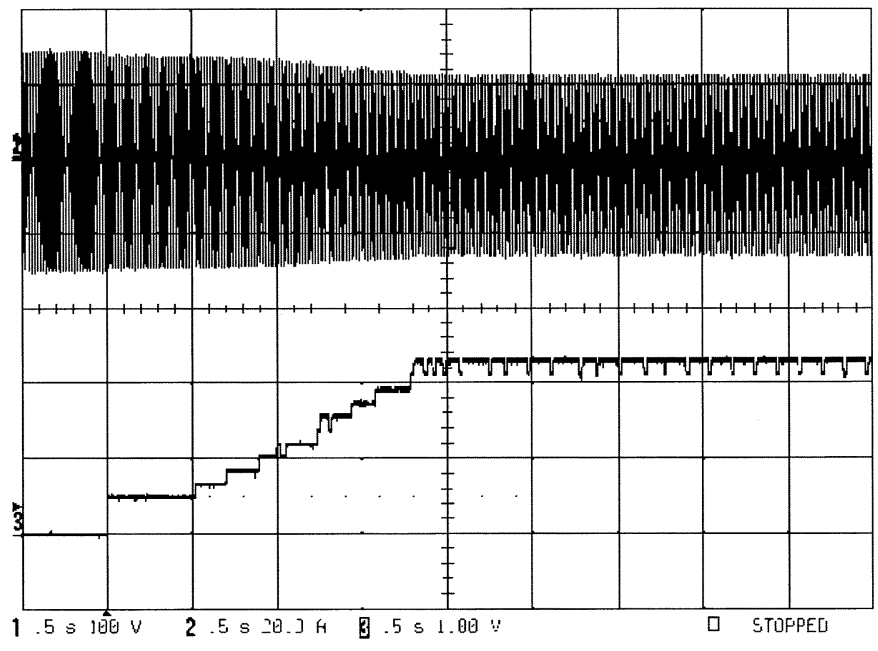

(a)

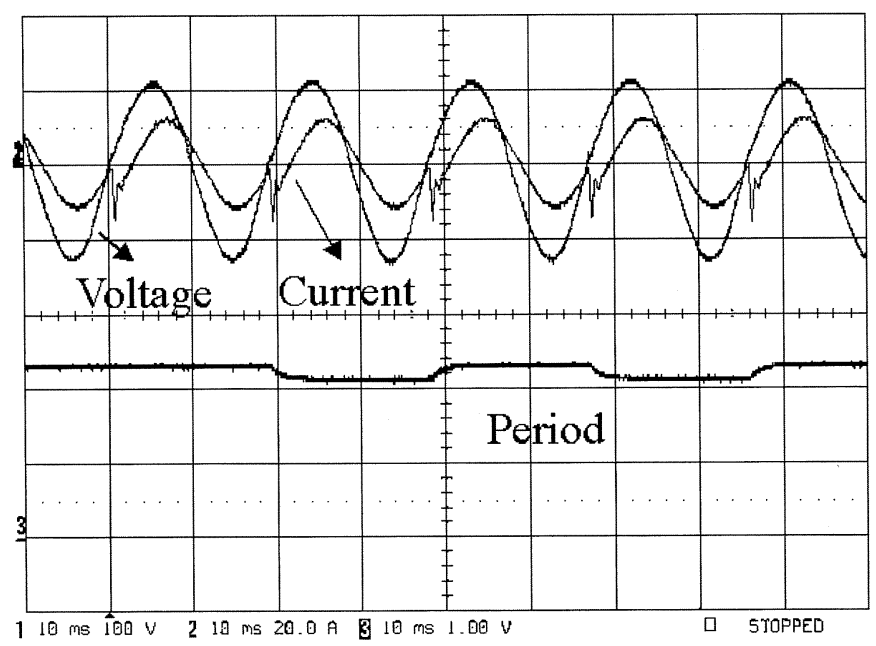

(b)

Fig. 8. Experimental result with APS; (a) frequency jump (b) detailed waveforms of the right-most part of subplot (a). (CH1: terminal voltage, 100 $\mathrm{V} /$ div; $\mathrm{CH} 2$ : inverter output current, $20 \mathrm{~A} /$ div; $\mathrm{CH} 3$ : period of terminal voltage, $1.2 \mathrm{~ms} / \mathrm{div}, 0 \mathrm{~V}$ represents $1 / 60 \mathrm{~Hz}$; TIME: $10 \mathrm{~ms} / \mathrm{div}$ ).

of terminal voltage keeps deviating until UFR or OFR is triggered when the utility is disconnected. The only shortcoming of this method would be that when the line frequency deviates from its nominal value, the inverter output current would not be in phase with the utility voltage. However, for a line frequency drift within $0.5 \mathrm{~Hz}$, the phase angle between the inverter output current and the utility voltage is only $4.1^{\circ}$ in the example above.

Still, there are other problems when treating islanding phenomenon. For example, an induction motor with large inertia is a kind of nonlinear load that is difficult to cope with [9]. Besides, if the utility obliges PV inverters to take part into grid voltage control, the phase angle of inverter current must vary with the terminal voltage magnitude dynamically. The assumption of unity-power-factor operation of PV inverters fails for the frequency-shift methods or APS and their effectiveness cannot be warranted. In fact, the islanding problem is so complicated that no single detection method has been proved analytically to solve it entirely. Combining various techniques with statistical evaluation [15], [16] may be another way to provide a complete solution.

\section{REFERENCES}

[1] "IEEE-P929: Recommended practice for utility interface of photovoltaic (PV) systems," in 7th Draft of IEEE Prestd. P929, Aug. 1988.

[2] Y. Takeda, K. Takigawa, H. Kobayashi, K. Nakahara, T. Morishita, A. Kitamura, A. Miyoshi, H. Matsuda, and S. Komatsu, "Test and study of utility interface and control problems for residential PV systems in Rokko island $200 \mathrm{~kW}$ test facility," in Proc. 20th IEEE Photovoltaic Specialists Conf., 1988, pp. 1062-1067.

[3] H. Kobayashi, K. Takigawa, E. Hashimoto, A. Kitamura, and H. Matsuda, "Problems and countermeasures on safety of utility grid with a number of small-scale PV systems," in Proc. 21st IEEE Photovoltaic Specialists Conf., 1990, pp. 850-855.

[4] - "Method for preventing phenomenon of utility grid with a number of small scale PV systems," in Proc. 22nd IEEE Photovoltaic Specialists Conf., 1991, pp. 695-700.

[5] A. Kitamura, M. Okamoto, K. Hotta, K. Takigawa, H. Kobayashi, and Y. Ariga, "Islanding prevention measures: Demonstration testing at Rokko test center for advanced energy systems," in Proc. 23rd IEEE Photovoltaic Specialists Conf., 1993, pp. 1063-1067.

[6] A. Kitamura, M. Okamoto, F. Yamamoto, K. Nakaji, H. Matsuda, and K. Hotta, "Islanding phenomenon elimination study at Rokko test center," in Proc. 24th IEEE Photovoltaic Specialists Conf., 1994, pp. 759-762.

[7] F. M. A. Ghali, "A combined technique for elimination of islanding phenomenon," in Proc. 25th IEEE Photovoltaic Specialists Conf., 1996, pp. 1473-1476.

[8] A. Kitamura, H. Matsuda, F. Yamamoto, and T. Matsuuoka, "Islanding phenomenon of grid connected PV systems," in Proc. 28th IEEE Photovoltaic Specialists Conf., 2000, pp. 1591-1594.

[9] M. E. Ropp, "Design Issues for Grid-Connected Photovoltaic Systems," Ph.D., Georgia Institute of Technology, Atlanta, GA, 1998.

[10] G. A. Kern, "Sunsine300, utility interactive ac module anti-islanding test results," in Proc. 26th IEEE Photovoltaic Specialists Conf., 1997, pp. 1265-1268.

[11] G. A. Smith, P. A. Onions, and D. G. Infield, "Predicting islanding operation of grid connected PV inverters," Proc. Inst. Elect. Eng.-Power Applicat., vol. 147, no. 1, pp. 1-6, Jan. 2000.

[12] M. E. Ropp, M. Begovic, and A. Rohatgi, "Analysis and performance assessment of the active frequency drift method of islanding prevention," IEEE Trans. Energy Conversion, vol. 14, pp. 810-816, Sept. 1999.

[13] A. Woyte, R. Belmans, K. U. Leuven, and J. Nijs, "Islanding of grid-connected ac module inverters," in Proc. 28th IEEE Photovoltaic Specialists Conf., 2000, pp. 1683-1686.

[14] M. E. Ropp, M. Begoviv, and A. Rohatgi, "Determining the relative effectiveness of islanding detection methods using phase criteria and nondetection zones," IEEE Trans. Energy Conversion, vol. 15, pp. 290-296, Sept. 2000.

[15] K. Takigawa and H. Kobayashi, "A development of compact and reliable protective control unit for grid connected small residential PV systems," in Proc. 24th IEEE Photovoltaic Specialists Conf., 1994, pp. 1081-1084.

[16] H. Kobayashi and K. Takigawa, "Statistical evaluation of optimun islanding preventing method for utility interface small scale dispersed PV systems," in Proc. 24th IEEE Photovoltaic Specialists Conf., 1994, pp. 1085-1088.

Guo-Kiang Hung was born in Taipei, Taiwan, R.O.C., in 1973. He received the B.S. and M.S. degrees from the Department of Electrical Engineering, National Taiwan University, Taipei, Taiwan, R.O.C., in 1995 and 1997, respectively. He is currently pursuing the Ph.D. degree at National Taiwan University.

His current research interests are in the analysis and design of digitally controlled photovoltaic inverters.

Chih-Chang Chang was born in Taichung, Taiwan, R.O.C., in 1974. He received the B.S.E.E. degree from National Taiwan University of Science and Technology, Taipei, Taiwan, R.O.C., in 1999, and the M.S.E.E. degree from National Taiwan University in 2001.

Currently, he is with AmbitMicrosystems Corporation, Hsinchu, Taiwan, R.O.C. His current research interests are in design and manufacturing of switching power circuits.

Chern-Lin Chen (S'86-M'90-SM'99) was born in 1962, in Taipei, Taiwan, R.O.C. He received the B.S. and Ph.D. degrees in electrical engineering from National Taiwan University, Taipei, Taiwan, R.O.C., in 1984 and 1987, respectively.

Currently, he is a Professor with the Department of Electrical Engineering, National Taiwan University, where he has been since 1987. His current research interests are in the areas of analysis, design, and application of power electronics converter and the electronic circuitry for plasma display panel. 